\title{
Euphorbia supina extract results in inhibition of high-fat-diet-induced obesity in mice
}

\author{
SARMILA NEPALI ${ }^{1}$, DO-KUK KIM ${ }^{2}$, HOON-YEON LEE ${ }^{2}$, HYEON-HUI KI ${ }^{1,2}$, BO-RAM KIM ${ }^{2}$, \\ SUNG-WOO HWANG ${ }^{2}$, MIN PARK ${ }^{2}$, DAE-KI KIM ${ }^{1}$ and YOUNG-MI LEE ${ }^{2}$ \\ ${ }^{1}$ Department of Immunology and Institute of Medical Sciences, Medical School, Chonbuk National University, \\ Jeonju, Jeollabuk 54907; ${ }^{2}$ Department of Oriental Pharmacy, College of Pharmacy and Wonkwang-Oriental \\ Medicines Research Institute, Wonkwang University, Iksan, Jeollabuk 54538, Republic of Korea
}

Received September 7, 2017; Accepted January 10, 2018

DOI: $10.3892 /$ ijmm.2018.3495

\begin{abstract}
The present study was undertaken to investigate the anti-obesity effect of a $50 \%$ ethanol extract of Euphorbia supina (ESEE) in high-fat-diet (HFD)-induced obese C57BL/6J mice. Mice were fed a HFD with or without ESEE $(2,10$, or $50 \mathrm{mg} / \mathrm{kg}$ ) or with Garcinia cambogia (positive control) for 6 weeks. ESEE supplementation significantly reduced body, epididymal white adipose tissue (eWAT), and organ weights $(\mathrm{P}<0.05)$. ESEE also reduced hepatic steatosis and improved serum lipid profiles. In addition, ESEE significantly reduced serum leptin levels and increased adiponectin levels, and significantly downregulated the mRNA and protein levels of proliferator-activated receptor $\gamma(\operatorname{PPAR} \gamma)$ and CCAAT/enhancer-binding protein alpha $(\mathrm{C} / \mathrm{EPB} \alpha)$ in eWAT and liver tissues (all $\mathrm{P}<0.05)$. These results suggested that ESEE supplementation protects against HFD-induced obesity by downregulating PPAR $\gamma$ and $\mathrm{C} / \mathrm{EPB} \alpha$, and that ESEE may be beneficial for the prevention and treatment of obesity and associated diseases.
\end{abstract}

\section{Introduction}

Obesity is a major health concern in developed countries, and is caused by an imbalance between energy intake and expenditure. Obesity is also known to be associated with various metabolic diseases, including hypertension, type 2 diabetes, cardiovascular diseases, atherosclerosis and various cancers (1-4). Adipocytes are the major cellular components of fat tissue, and excessive fat tissue growth, hypertrophy and

Correspondence to: Professor Young-Mi Lee, Department of Oriental Pharmacy, College of Pharmacy and Wonkwang-Oriental Medicines Research Institute, Wonkwang University, 460 Iksandae Road, Iksan, Jeollabuk 54538, Republic of Korea

E-mail: ymlee@wku.ac.kr

Key words: Euphorbia supina, high fat diet, obesity, peroxisome proliferator-activated receptor- $\gamma$, CCAAT-enhancer binding proteins- $\alpha$ adipocyte differentiation are fundamental characteristics of obesity (5). The accumulation of lipid droplets in adipocytes has an important role in lipid metabolism and regulation (6), and the differentiation of preadipocytes is regulated by transcription factors, such as peroxisome proliferator-activated receptor- $\gamma(\mathrm{PPAR} \gamma)$ and CCAAT/enhancer-binding protein- $\alpha$ $(\mathrm{C} / \mathrm{EBP} \alpha)(7,8)$.

Numerous methods, including diet control, exercise and medication, have been suggested to prevent and treat obesity (9). However, many clinically available drugs have side effects such as constipation, anorexia, dizziness, and insomnia, which remain issues of concern (10). To avoid the side effects of pharmacological agents, there is a need for substitute therapies with minimum side-effects, perhaps based on herbal or natural products (11).

Euphorbia supina (E. supina) belongs to the Euphorbiaceae family and is used in traditional medicine to treat a variety of diseases, such as bronchitis, jaundice, hemorrhage, and several gastrointestinal diseases $(12,13)$. It has also been reported that E. supina contains various biologically active compounds like tannins, terpenoids and polyphenols (14), and polyphenols with antioxidant properties (15). Furthermore, a recent study revealed that E. supina polyphenol mixtures inhibit the invasion and metastasis of breast cancer cells (16). However, to the best of our knowledge, no scientific evidence has yet been presented regarding the anti-obesity effect of E. supina. The purpose of the present study was to investigate the anti-obesity effect of E. supina and the mechanism underlying its inhibitory effect on adipogenesis.

\section{Materials and methods}

Materials and reagents. TRIzol reagent and SuperScript III kit were obtained from Invitrogen (Thermo Fisher Scientific, Inc., Waltham, MA, USA). Mouse primary antibodies against PPAR $\gamma$ (sc-7273), C/EBP $\alpha$ (sc-166258) and $\beta$-actin (sc-47778), and goat-anti-mouse horseradish peroxidase (HRP)-conjugated secondary antibodies (sc-2030) were purchased from Santa Cruz Biotechnology, Inc. (Dallas, TX, USA). Primary antibodies were diluted to 1:1,000 and secondary antibodies at 1:5,000. Garcinia cambogia (GC) extract was purchased from Prakruti Products Pvt. Ltd. (Karnataka, India). 
Preparation of the ethanol extract of E. supina (ESEE). E. supina was obtained from Gungangbogam (Jechon, Korea). The dried and powdered fruit of E. supina $(500 \mathrm{~g})$ were extracted using $50 \%$ ethanol for $2 \mathrm{~h}$ under mantle-reflux at $80^{\circ} \mathrm{C}$. Following filtration, and solvent removal on a rotary vacuum evaporator (N-000; EYELA; Tokyo Rikakikai Co., Ltd., Tokyo, Japan) ESEE was obtained as a powder (17). The yield of ESEE obtained using this procedure was $83.5 \mathrm{~g}(16.7 \% \mathrm{wt} / \mathrm{wt})$. ESEE was stored at $4^{\circ} \mathrm{C}$ until required.

Animal treatment. Male C57BL/6 mice ( $\mathrm{n}=36$; weight, 20.4 $\pm 1.03 \mathrm{~g}$; age, 5 weeks) were purchased from Samtako Bio Korea (Samtako Bio Korea, Osan, Korea). Experimental procedures were conducted according to a protocol approved by the institutional animal care committee of Chonbuk National University. Mice were housed at $22 \pm 2{ }^{\circ} \mathrm{C}, 50 \pm 5 \%$ humidity and provided a normal diet and water ad libitum. Following a 1-week acclimation period, mice were divided into six groups ( $n=6$ each), as follows: i) the normal diet (ND) group, fed with normal standard diet containing $14 \%$ fat, $21 \%$ protein and $65 \%$ carbohydrate (5L79; Orient Bio, Inc., Seongnam, Korea); ii) the high-fat diet (HFD) group, fed with HFD containing $60 \%$ fat, $20 \%$ protein and 20\% carbohydrate (D12492; Research Diets, Inc., New Brunswick, NJ, USA); iii) the HFD+ESEE (2) group, fed with HFD and treated with ESEE ( $2 \mathrm{mg} / \mathrm{kg} /$ daily); iv) the HFD+ESEE (10) group, fed with HFD and treated with ESEE (10 mg/kg/daily); v) the HFD+ESEE (50) group, fed with HFD and treated with ESEE (50 mg/kg/daily); vi) the HFD+GC group, fed with HFD and treated with GC (200 mg/kg/daily). ESEE or GC was administered daily via oral gavage for 6 weeks. Body weights and amounts of food consumed were determined weekly.

Determination of abdominal fat volume by micro-computed tomography (micro-CT). Following the 6-week treatment period, mice were starved for $6 \mathrm{~h}$ prior to sacrifice and anesthetized via intraperitoneal injection of ketamine $(75 \mathrm{mg} / \mathrm{kg}$; Yuhan Corporation, Seoul, Korea) and rompun (15 mg/kg; Bayer Korea Ltd., Seoul, Korea). Images were acquired using a Skyscan-1076 micro-CT scanner (Bruker microCT, Kontich, Belgium). CT was performed using a pixel size of $35 \mu \mathrm{m}$, a source voltage of $50 \mathrm{kVp}$, and a source current of $200 \mu \mathrm{A}$. The $\mathrm{X}$-ray detector contained a 12-bit, water-cooled charge-coupled device camera with a resolution of 4,000x2,300 pixels and a scintillator. Images were acquired at 0.6 degrees and an exposure time of $0.46 \mathrm{sec}$ using a $1-\mathrm{mm}$ aluminum energy filter. Mice were sacrificed following micro-CT scanning and abdominal fat volumes were measured using an Olympus SP-500 UZ camera (Olympus Corporation, Tokyo, Japan). Following micro-CT, under anesthesia, mice were euthanized via intracardiac puncture. Blood was collected $(0.8-0.9 \mathrm{ml})$ via cardiac puncture followed by removal of organs such as liver, kidney and spleen. Following exsanguination, mortality was confirmed by incising the heart and ensuring that no respiratory movement occurred for $\geq 3 \mathrm{~min}$.

Hematoxylin and eosin $(H \& E)$ staining. Liver tissue and epididymal white adipose tissue (eWAT) were fixed using
$10 \%$ neutral buffered formalin at room temperature for $8 \mathrm{~h}$, embedded in paraffin wax, and cut serially into $10-\mu \mathrm{m}$ sections. Sections were stained with H\&E at room temperature (hematoxylin, $4 \mathrm{~min}$; eosin, $2 \mathrm{~min}$ ) and histologic alterations were observed and photographed under a light microscope (magnification, x100; Olympus CX21; Olympus Corporation) (18).

Biochemical analysis. To evaluate hepatic steatosis, levels of hepatic total triglycerides (TG) and cholesterol (TC) were determined by homogenizing liver tissues in a chloroform/methanol mixture $(2: 1, \mathrm{v} / \mathrm{v})$. TG and TC concentrations were then measured using commercially available kits (TG; AM 1575-K; TC; AM 202-K; Asan Pharmaceutical Co., Ltd., Seoul, Korea) as detailed previously (19). In addition, rapid enzymatic assay kits were used to measure serum levels of TC, TG and high-density lipoprotein cholesterol (HDL-c; AM 203-K; Asia Pharmaceutical Co., Ltd., Seoul, Korea), and low density lipoprotein cholesterol (LDL-c) was calculated using Friedewald's formula (20) as follows: LDL-c=TC-(HDL-c+TG/5).

ELISA kits were used to measure leptin (ADI-900-019A; Enzo Life Sciences Inc., Farmingdale, NY, USA) and adiponectin (47-ADPMS-E01; R\&D Systems, Inc., Minneapolis, MN, USA). HFD-induced liver damage was assessed by measuring the serum enzyme activities of alanine transaminase (ALT) and aspartate aminotransferase (AST) using the ALT/AST cassette test kit (Alere Cholestech LDX ${ }^{\circledR}$ System; Alere, Inc., Waltham, MA, USA) (18).

Reverse transcription-quantitative polymerase chain reaction (RT-qPCR). Total RNA was extracted from eWAT and liver tissues using TRIzol RNA Isolation Reagent, according to the manufacturer's instructions. The synthesis of cDNA was performed with $2 \mu \mathrm{g}$ RNA using the SuperScript III First Strand Synthesis kit protocol. qPCR was performed using the ABI Real-Time PCR system (Applied Biosystems; Thermo Fisher Scientific, Inc.) using SYBR Green PCR Master Mix (Thermo Fisher Scientific, Inc.). PCR was performed using the following conditions: $95^{\circ} \mathrm{C}$ for $10 \mathrm{~min}$ followed by 40 cycles of denaturation at $95^{\circ} \mathrm{C}$ for $15 \mathrm{sec}$, and annealing at $60^{\circ} \mathrm{C}$ for $1 \mathrm{~min}$, as detailed previously (21). Primer sequences were as follows: GAPDH, forward 5'-CATGGCCTTCCG TGTTC-3' and reverse 5'-CCTGGTCCTCAGTGTAGC-3'; PPAR $\gamma$, forward 5'-GATGGAAGACCACTCGCATT-3') and reverse 5'-AACCATTGGGTCAGCTCTTG-3'; and C/EBP $\alpha$, forward 5'-TTGTTTGGATTTATCTCGGC-3' and reverse 5'-CCAAGAAGTCGGTGGACAAG-3'. The comparative quantification cycle method was used to measure the relative quantitation of each gene and mRNA levels were normalized with GAPDH, as detailed previously (6).

Western blot analysis. eWAT and liver tissues were lysed in ice-cold radioimmunoprecipitation assay buffer (sc-24948; Santa Cruz Biotechnology, Inc., CA, USA) for $40 \mathrm{~min}$ and centrifuged $(12,000 \mathrm{x} \mathrm{g})$ for $20 \mathrm{~min}$ at $4^{\circ} \mathrm{C}$, as detailed previously (21). Protein quantification was determined via bicinchoninic acid assay and protein samples (20 $\mu \mathrm{g} /$ lane) were separated by $8 \%$ SDS-PAGE and transferred to polyvinylidene difluoride membranes (GE Healthcare, Chicago, IL, 

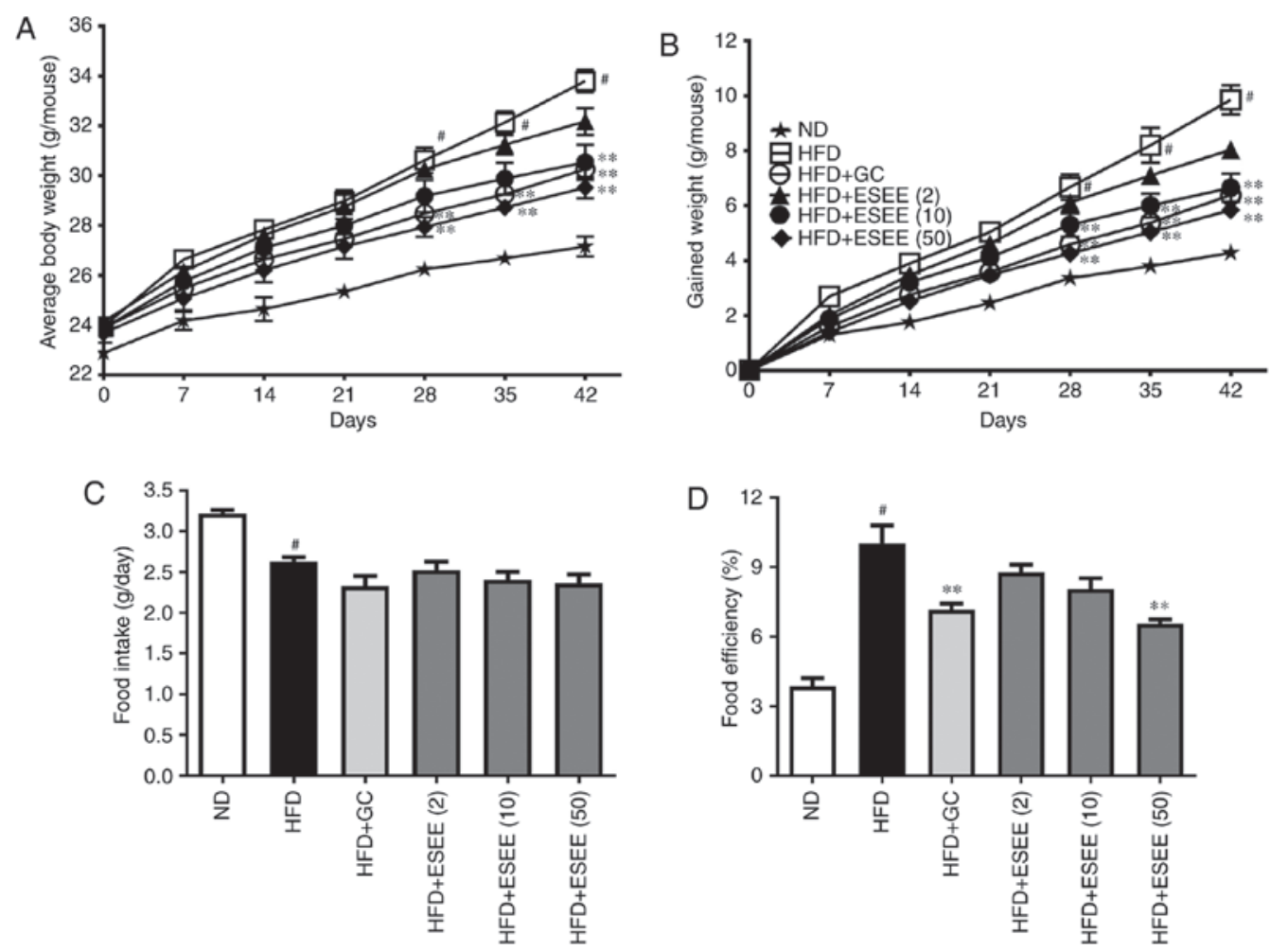

Figure 1. Effects of ESEE on body weight, food intake and food conversion efficiency in HFD-fed mice. (A) Mean body weight, (B) gained body weight, (C) mean food intake per day and (D) food conversion efficiency were measured weekly. Results are presented as the mean + or \pm the standard error of the mean $(\mathrm{n}=6) .{ }^{*} \mathrm{P}<0.05$ vs. ND; "P $<0.05$ and ${ }^{* *} \mathrm{P}<0.01$ vs. HFD. ESEE, ethanol extract of Euphorbia supine; HFD, high-fat diet; ND, normal diet; (2), $2 \mathrm{mg} / \mathrm{kg}$; (10), $10 \mathrm{mg} / \mathrm{kg}$; (50), $50 \mathrm{mg} / \mathrm{kg}$; GC, Garcinia cambogia.

USA), which were then blocked with 5\% skimmed milk in tris-buffered saline containing $0.1 \%$ Tween-20 (TBST) for $1 \mathrm{~h}$ at room temperature. Membranes were then probed with primary antibodies at $4^{\circ} \mathrm{C}$ overnight, washed with TBST 4 times, incubated at room temperature with HRP-conjugated secondary antibody for $45 \mathrm{~min}$, and rewashed with TBST 3 times. Proteins were visualized using an enhanced chemiluminescence detection kit (EMD Millipore, Bedford, MA, USA) and a Fusion FX7 imaging system (Vilber Lourmat, Marne-la-Vallée, France).

Ultra-pressure liquid chromatography (UPLC). UPLC was performed using an ACQUITY UPLC BEH C18 column $(2.1 \times 50 \mathrm{~mm}, 1.7 \mu \mathrm{m})$ and a photodiode array detector (Waters Corporation, Milford, MA, USA), as detailed previously (17). Elution was performed at a flow rate of $0.15 \mathrm{ml} / \mathrm{min}$ using distilled water containing $0.1 \%$ formic acid (solvent $\mathrm{A}$ ) and acetonitrile containing $0.1 \%$ formic acid (solvent $\mathrm{B}$ ) in gradient mode (B 5\% from 0-1 min, B 5-95\% from 1-16 min, B 95-100\% from 16-18 $\mathrm{min}$, and B 100\% from 18-26 min at a flow rate of $0.15 \mathrm{ml} / \mathrm{min}$ at $25^{\circ} \mathrm{C}$. Detection was performed at a wavelength of $330 \mathrm{~nm}$.

Statistical analysis. Data are presented as the mean + or \pm standard error of the mean, and were analyzed using GraphPad Prism software (version 5.0; GraphPad Software, Inc., La Jolla, CA, USA). One-way analysis of variance was used to measure the significant difference followed by Tukey's post hoc test for comparison of means. $\mathrm{P}<0.05$ was considered to indicate a statistically significant difference.

\section{Results}

ESEE reduces body weight gain in HFD-fed mice. To investigate the anti-obesity effect of ESEE, mice were fed HFD with or without ESEE (2, 10 and $50 \mathrm{mg} / \mathrm{kg}$, oral gavage daily) or with GC (200 mg/kg, oral gavage daily) for 6 weeks. Food intake and body weights were recorded once weekly. At the end of the 6-week treated period, HFD mice had a mean body weight gain of $41.2 \%$, whereas ND mice exhibited a gain of $18.7 \%$. Mean percentage body weight gain of HFD mice was significantly reduced by ESEE $(50 \mathrm{mg} / \mathrm{kg}$ ) supplementation (Fig. 1A and B). In addition, no significant difference in dietary intake was observed among the HFD-fed and ESEE administered groups (Fig. 1C), but $50 \mathrm{mg} / \mathrm{kg}$ ESEE significantly reduced the food conversion efficiency as compared with HFD-fed mice (Fig. 1D). These results indicate that ESEE induced adipose weight loss, and reduced body weight gain and the percentage of food efficiency.

ESEE reduces fat deposition in organs in HFD-fed mice. Micro-CT analysis results demonstrated that orbital fat volume percentage was significantly lower in ESEE (10 and $50 \mathrm{mg} / \mathrm{kg}$ ) treated mice than in HFD-fed mice(Fig.2A and B). Furthermore, the effects of ESEE supplementation on fat accumulation in eWAT, liver, spleen and kidneys were investigated. The results demonstrated that these organs were significantly heavier in HFD mice than in ND mice, and that ESEE treatment significantly reduced fat deposition in these organs, compared with HFD-fed mice (Fig. 2C-G). 
A
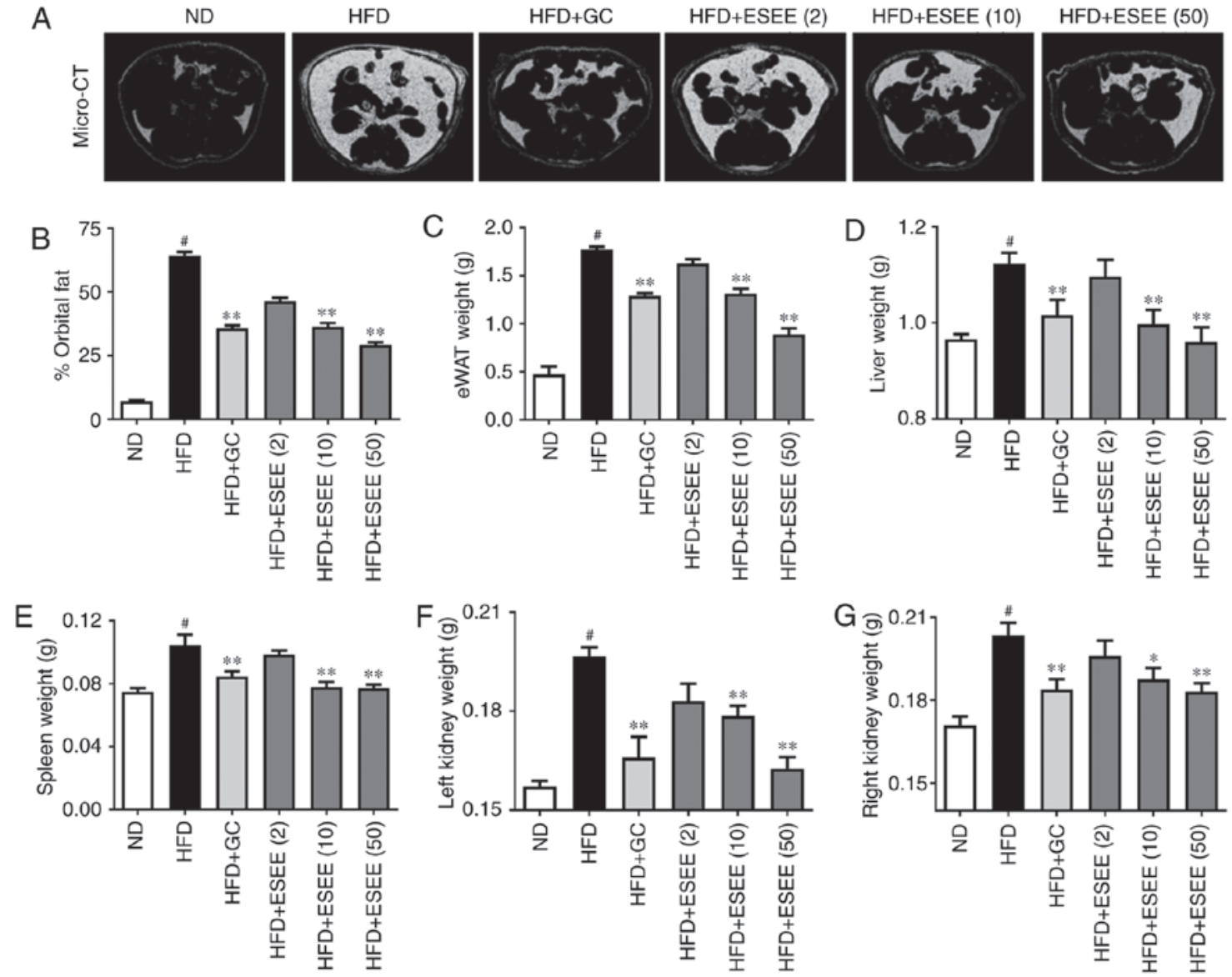

Figure 2. Effect of ESEE on fat deposition and organ weight in HFD-induced obese mice. (A) Representative micro-CT images of mice in each group. (B) Percentage of orbital fat were determined by micro-CT. (C) eWAT (D) liver (E) spleen (F) left kidney and (G) right kidney were obtained following sacrifice and weighed. Results are presented as the mean + or \pm the standard error of the mean $(\mathrm{n}=6)$. ${ }^{*} \mathrm{P}<0.05$ vs. ND; ${ }^{*} \mathrm{P}<0.05$ and ${ }^{* *} \mathrm{P}<0.01$ vs. HFD. ESEE, ethanol extract of Euphorbia supine; HFD, high-fat diet; CT, computed tomography; eWAT, epididymal white adipose tissue; ND, normal diet; (2), 2 mg/kg; (10), $10 \mathrm{mg} / \mathrm{kg}$; (50), $50 \mathrm{mg} / \mathrm{kg}$; GC, Garcinia cambogia.

ESEE suppresses histological changes in the eWAT and liver tissues of HFD-fed mice. Increases in lipid accumulations in the liver and eWAT are commonly observed in HFD-fed obese mice (17). H\&E staining revealed enlarged or hypertrophic eWAT in the HFD group, and smaller eWAT sizes in ESEE supplemented mice (Fig. 3A). In addition, the histological study revealed enlarged hepatocytes, as evidenced by excessive vacuolation in the HFD group as compared with the ND group. As presented in Fig. 3B, ESEE markedly reduced vacuolization and lipid droplet numbers in the liver tissues of HFD mice. Hepatic steatosis was determined by measuring hepatic TG and TC levels. The present results demonstrated that ESEE (10 and $50 \mathrm{mg} / \mathrm{kg}$ ) supplementation significantly reduced HFD-induced levels of TG and TC in liver tissues (Fig. 3C and D). Serum ALT and AST levels were also measured, which are clinical markers of liver damage. The results indicated that ESEE significantly reduced the HFD-induced serum levels of AST and ALT compared with the HFD group (Fig. 3E and F). These data indicate that ESEE inhibited HFD-induced hepatic steatosis and serum liver enzymes.

ESEE improves biochemical parameters of blood in HFD-fed mice. HFD-fed mice exhibited significantly higher serum levels of TC, low-density lipoprotein cholesterol (LDL-c) and TG, and significantly lower levels of high-density lipoprotein cholesterol (HDL-c) than mice in the ND group. ESEE significantly inhibited TC (50 mg/ kg), LDL-c (10 and $50 \mathrm{mg} / \mathrm{kg}$ ) and $\mathrm{TG}(50 \mathrm{mg} . \mathrm{kg})$ increases, and increased HDL-c levels (10 and $50 \mathrm{mg} / \mathrm{kg}$ ) vs. HFD-fed mice (Fig. 4A-D). Furthermore, ESEE significantly inhibited leptin levels and increased adiponectin levels. At a dose of $50 \mathrm{mg} / \mathrm{kg}$, ESEE decreased mean leptin levels by $64.7 \%$ (Fig. 4E) and increased mean adiponectin levels by $51.1 \%$ compared with the HFD group (Fig. 4F).

ESEE inhibits transcription factors of adipogenesis in HFD-fed mice. RT-qPCR and western blotting were performed to measure the mRNA and protein expressions, respectively, of transcription factors of adipogenesis, such as PPAR $\gamma$ and $\mathrm{C} / \mathrm{EBP} \alpha$. The results demonstrated that ESEE (10 and $50 \mathrm{mg} / \mathrm{kg}$ ) significantly inhibited the mRNA and protein expressions of PPAR $\gamma$ and $\mathrm{C} / \mathrm{EBP} \alpha$ in eWAT tissues (Fig. 5) and liver tissues (Fig. 6), as compared with the HFD group.

Chemical components of ESEE by UPLC. UPLC assay demonstrated that corilagin and ellagic acid were the main components of ESEE (Fig. 7). However, other peaks observed were unidentified and require further study. 
A a

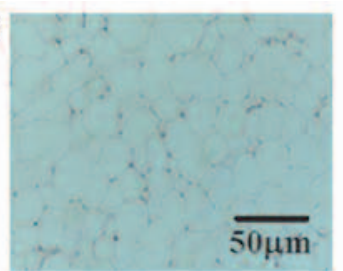

d

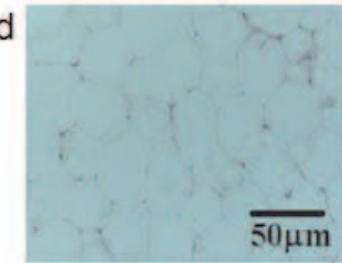

B a

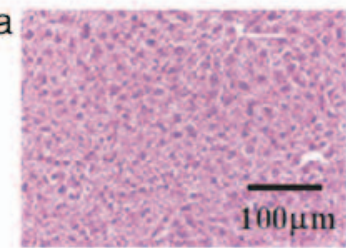

d

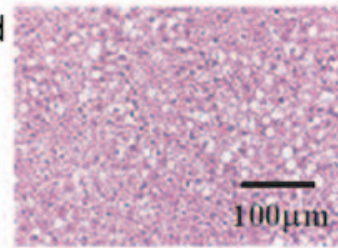

b

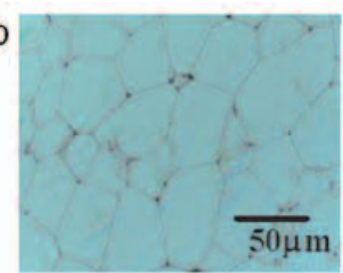

e
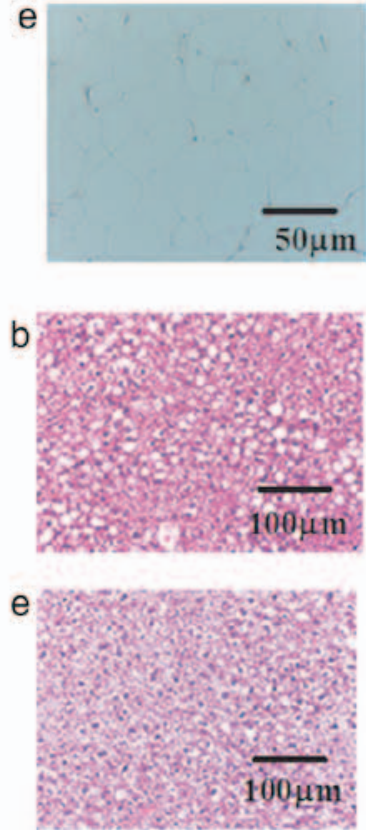
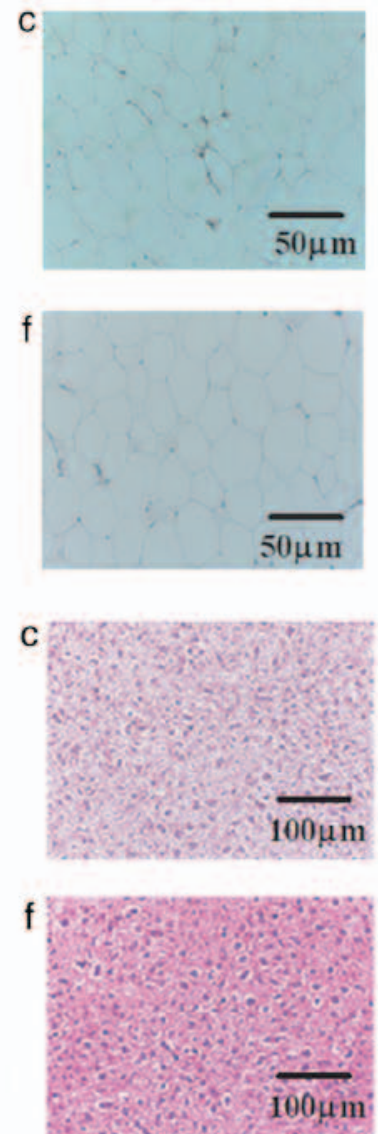

C

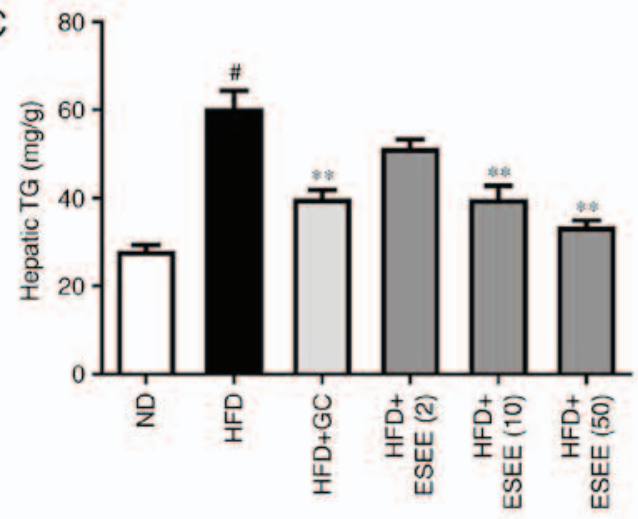

E

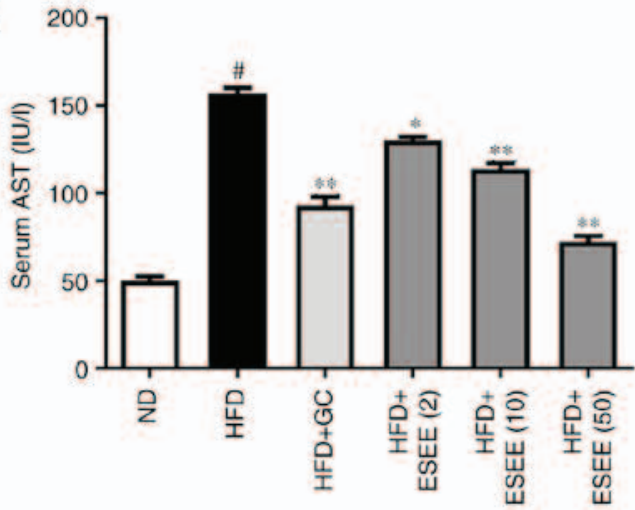

D

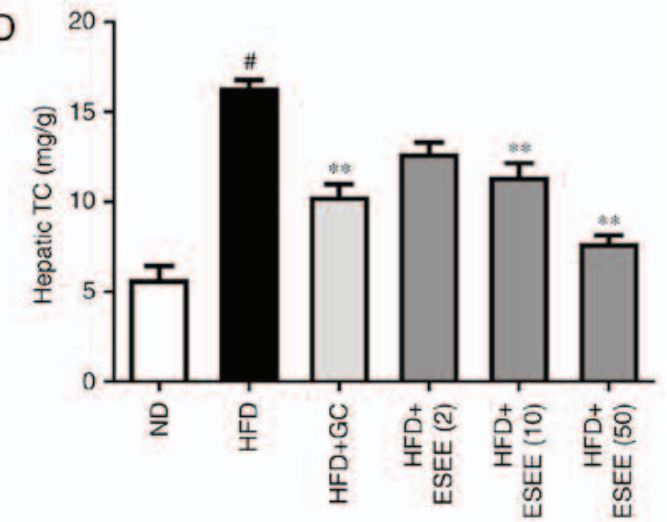

$\mathrm{F}$

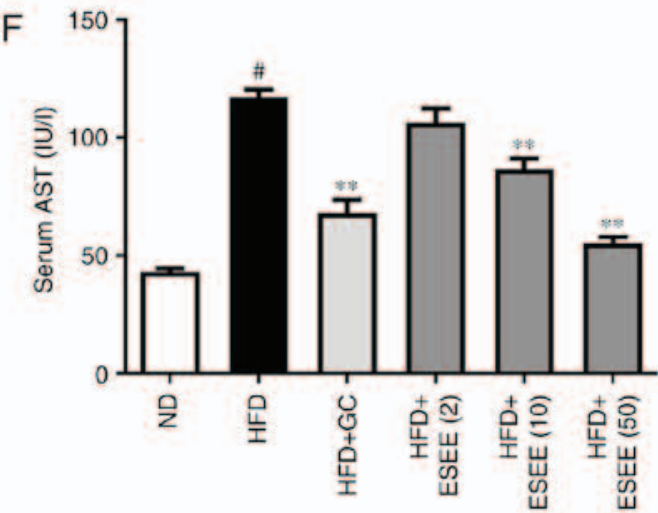

Figure 3. Effect of ESEE on histological changes and lipid accumulations in eWAT and liver tissues of HFD-induced obese mice. Histological changes were determined via H\&E staining in (A) eWAT and (B) liver tissue sections (magnification, x100) of mice from the (a) ND, (b) HFD, (c) HFD+GC, (d) HFD+ESEE (2), (e) HFD+ESEE (10) and (f) HFD+ESEE (50)-fed mice. Lipid accumulation in liver was assessed by measuring hepatic (C) TG and (D) TC levels. Serum levels of (E) AST and (F) ALT were measured using commercial kits. Results are presented as the mean + the standard error of the mean ( $\mathrm{n}=6)$. ${ }^{\text {}} \mathrm{P}<0.05$ vs. ND; ${ }^{*} \mathrm{P}<0.05$ and ${ }^{* *} \mathrm{P}<0.01$ vs. HFD. ESEE, ethanol extract of Euphorbia supine; HFD, high-fat diet; eWAT, epididymal white adipose tissue; ND, normal diet; (2), $2 \mathrm{mg} / \mathrm{kg}$; (10), $10 \mathrm{mg} / \mathrm{kg}$; (50), $50 \mathrm{mg} / \mathrm{kg}$; GC, Garcinia cambogia; TG, total triglycerides; TC, total cholesterol; AST, aspartate aminotransferase; ALT, alanine transaminase. 

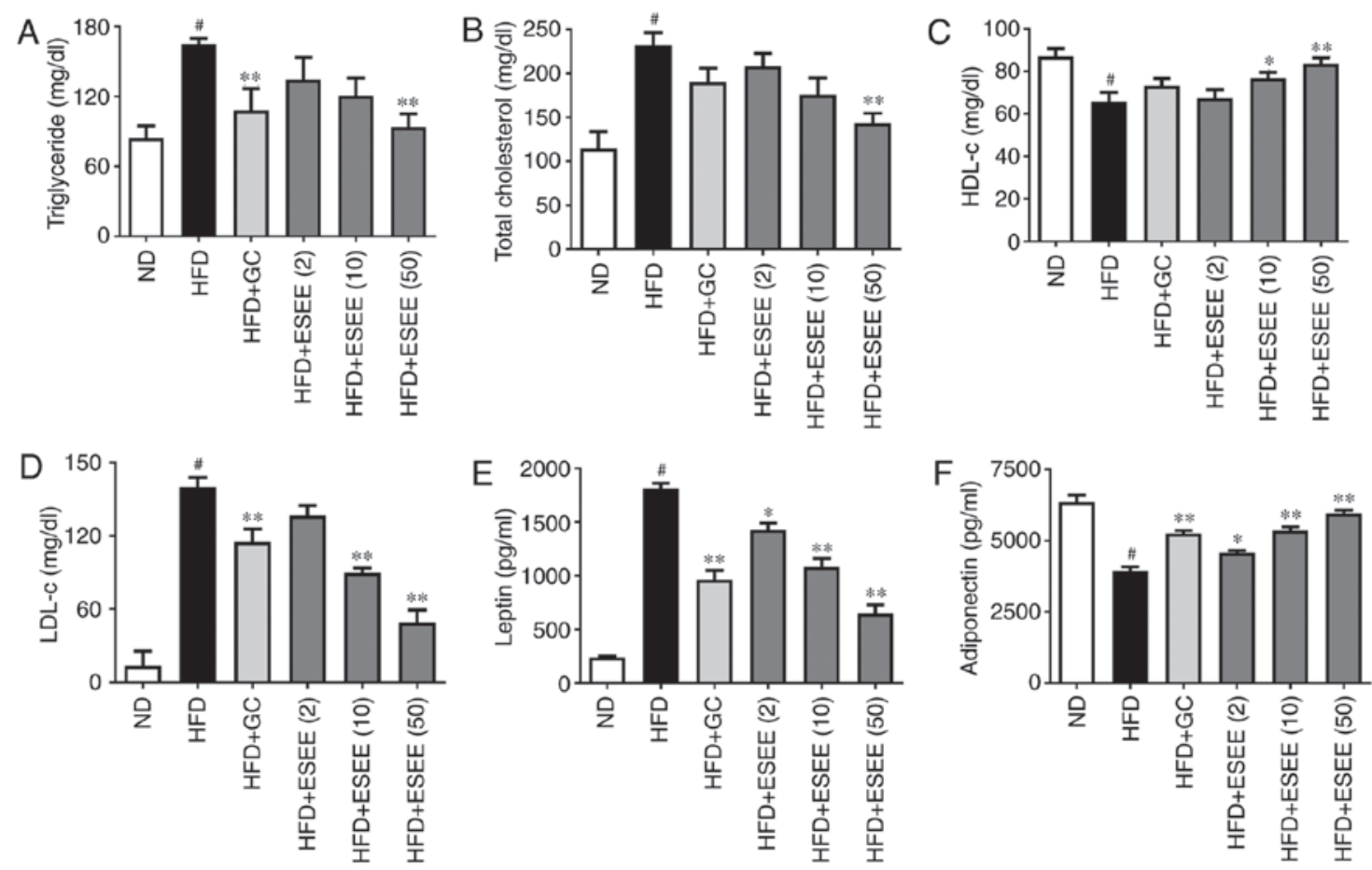

Figure 4. Effect of ESEE on blood biochemical parameters in HFD-fed mice. Enzymatic methods were used to measure serum levels of (A) triglyceride (B) total cholesterol (C) HDL-c, and (D) LDL-c. ELISA was used to measure serum levels of (E) leptin and (F) adiponectin. Results are presented as the mean + the standard error of the mean $(\mathrm{n}=6) .{ }^{*} \mathrm{P}<0.05$ vs. ND; ${ }^{*} \mathrm{P}<0.05$ and ${ }^{* *} \mathrm{P}<0.01$ vs. HFD. ESEE, ethanol extract of Euphorbia supine; HFD, high-fat diet; HDL-c, high-density lipoprotein cholesterol; LDL-c, low-density lipoprotein cholesterol; ND, normal diet; (2), $2 \mathrm{mg} / \mathrm{kg} ;(10), 10 \mathrm{mg} / \mathrm{kg}$; (50), 50 mg/kg; GC, Garcinia cambogia.
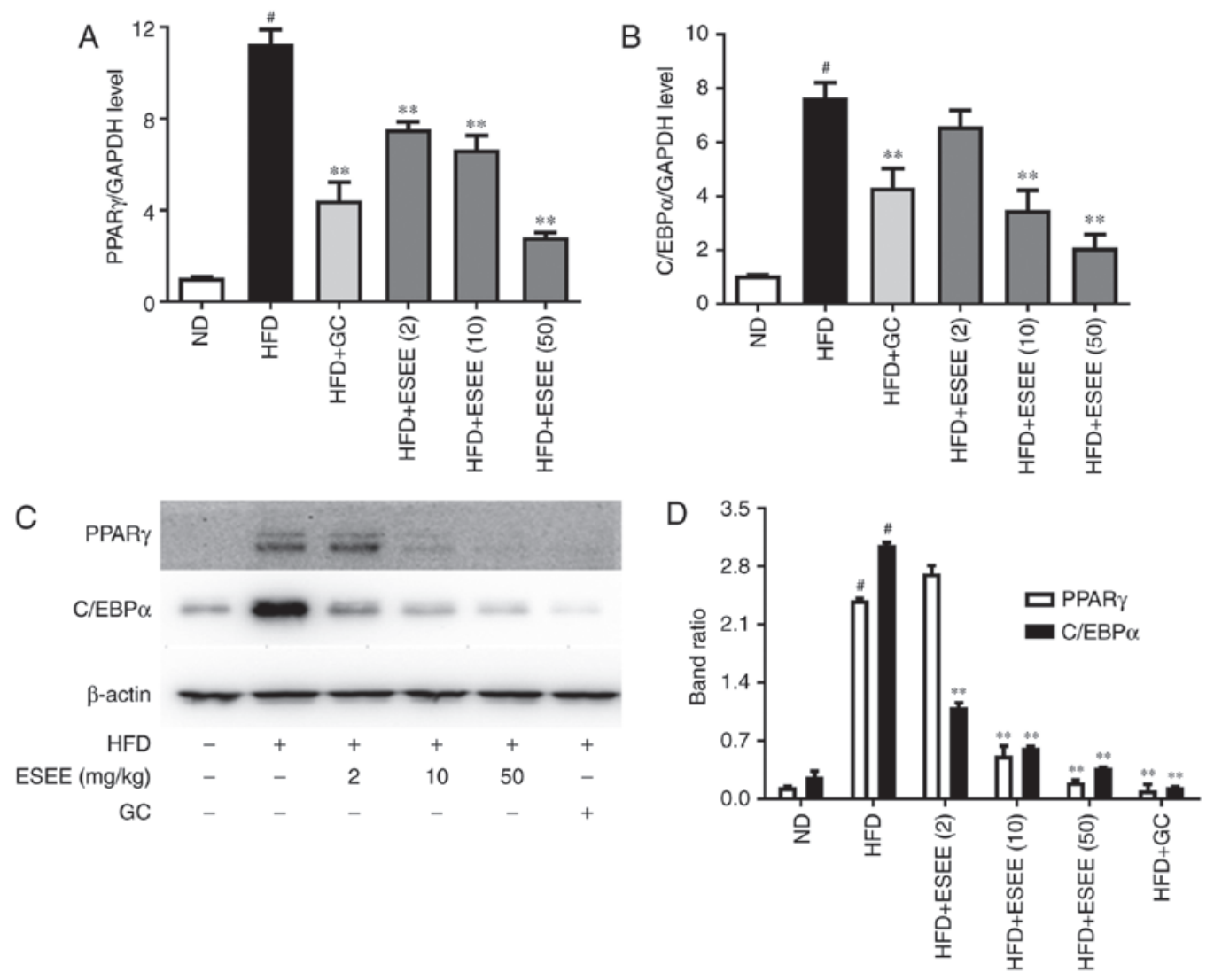

Figure 5. Effect of ESEE on PPAR $\gamma$ and C/EBP $\alpha$ expressions in eWAT tissues of HFD-induced obese mice. Reverse transcription-quantitative polymerase chain reaction was performed to measure mRNA levels of (A) PPAR $\gamma$ and (B) C/EBP $\alpha$. Western blotting was used to determine the protein expressions of (C) PPAR $\gamma$ and $\mathrm{C} / \mathrm{EBP} \alpha$. (D) Relative band intensities of blots from three experiments. Results are presented as the mean + the standard error of the mean $(\mathrm{n}=6) .{ }^{*} \mathrm{P}<0.05$ vs. ND; ${ }^{*} \mathrm{P}<0.05$ and ${ }^{* *} \mathrm{P}<0.01$ vs. HFD. ESEE, ethanol extract of Euphorbia supine; HFD, high-fat diet; PPAR $\gamma$, peroxisome proliferator-activated receptor- $\gamma$; $\mathrm{C} / \mathrm{EBP} \alpha, \mathrm{CCAAT} / \mathrm{enhancer-binding} \mathrm{protein-} \alpha$;D, normal diet; (2), $2 \mathrm{mg} / \mathrm{kg} ;(10), 10 \mathrm{mg} / \mathrm{kg} ;(50), 50 \mathrm{mg} / \mathrm{kg} ; \mathrm{GC}$, Garcinia cambogia. 

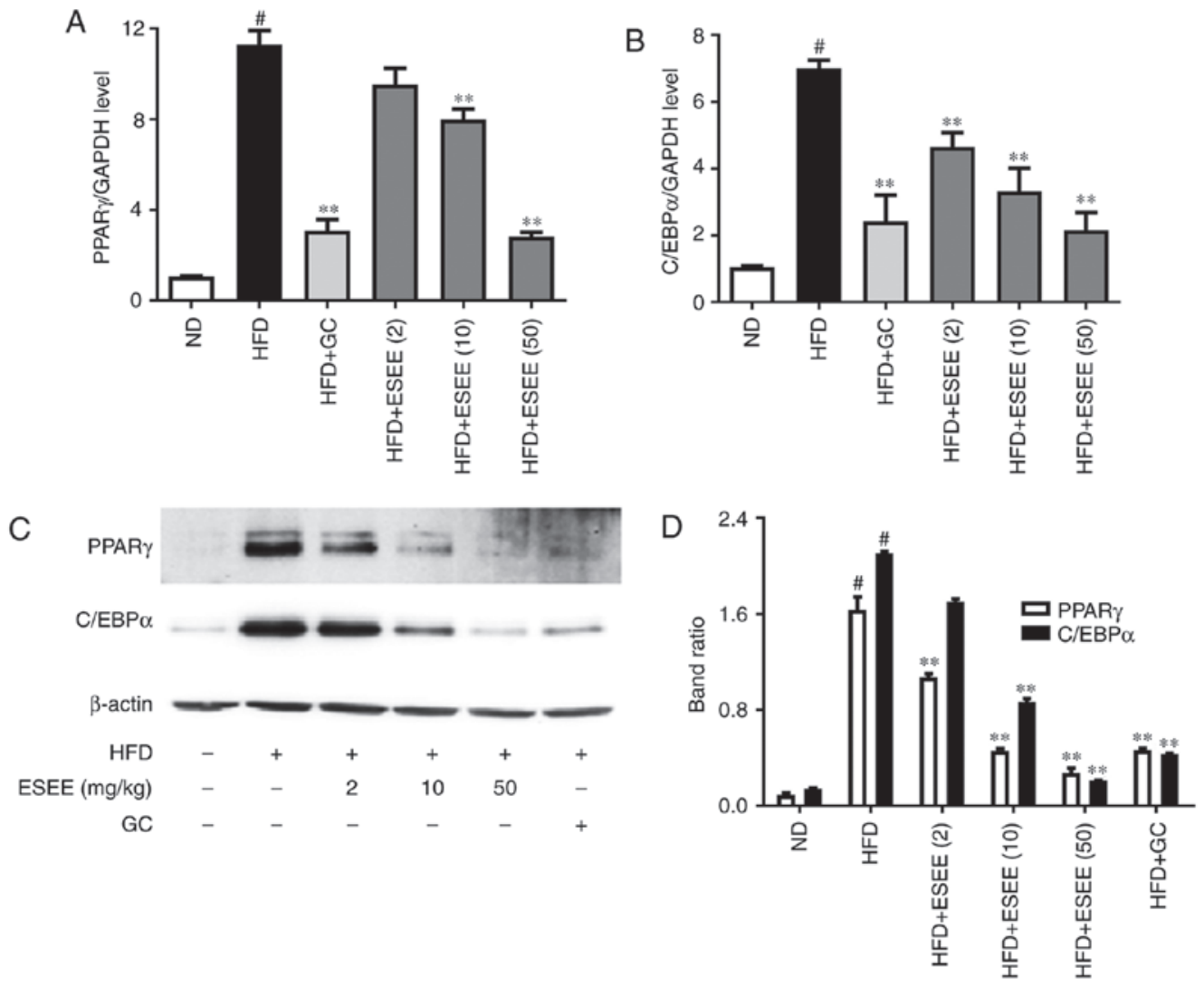

Figure 6. Effect of ESEE on PPAR $\gamma$ and C/EBP $\alpha$ expressions in the liver tissues of HFD-induced obese mice. Reverse transcription-quantitative polymerase chain reaction was performed to measure mRNA levels of (A) PPAR $\gamma$ and (B) C/EBP $\alpha$. Western blotting was used to assess the protein expressions of (C) PPAR $\gamma$ and $\mathrm{C} / \mathrm{EBP} \alpha$. (D) Relative band intensities of blots from three experiments. ${ }^{~} \mathrm{P}<0.05$ vs. ND; ${ }^{\mathrm{P}}<0.05$ and ${ }^{\text {*** }} \mathrm{P}<0.01$ vs. HFD. ESEE, ethanol extract of Euphorbia supine; HFD, high-fat diet; PPAR $\gamma$, peroxisome proliferator-activated receptor- $\gamma$; C/EBP $\alpha$, CCAAT/enhancer-binding protein- $\alpha$; ND, normal diet; (2), $2 \mathrm{mg} / \mathrm{kg}$; (10), $10 \mathrm{mg} / \mathrm{kg}$; (50), $50 \mathrm{mg} / \mathrm{kg}$; GC, Garcinia cambogia.
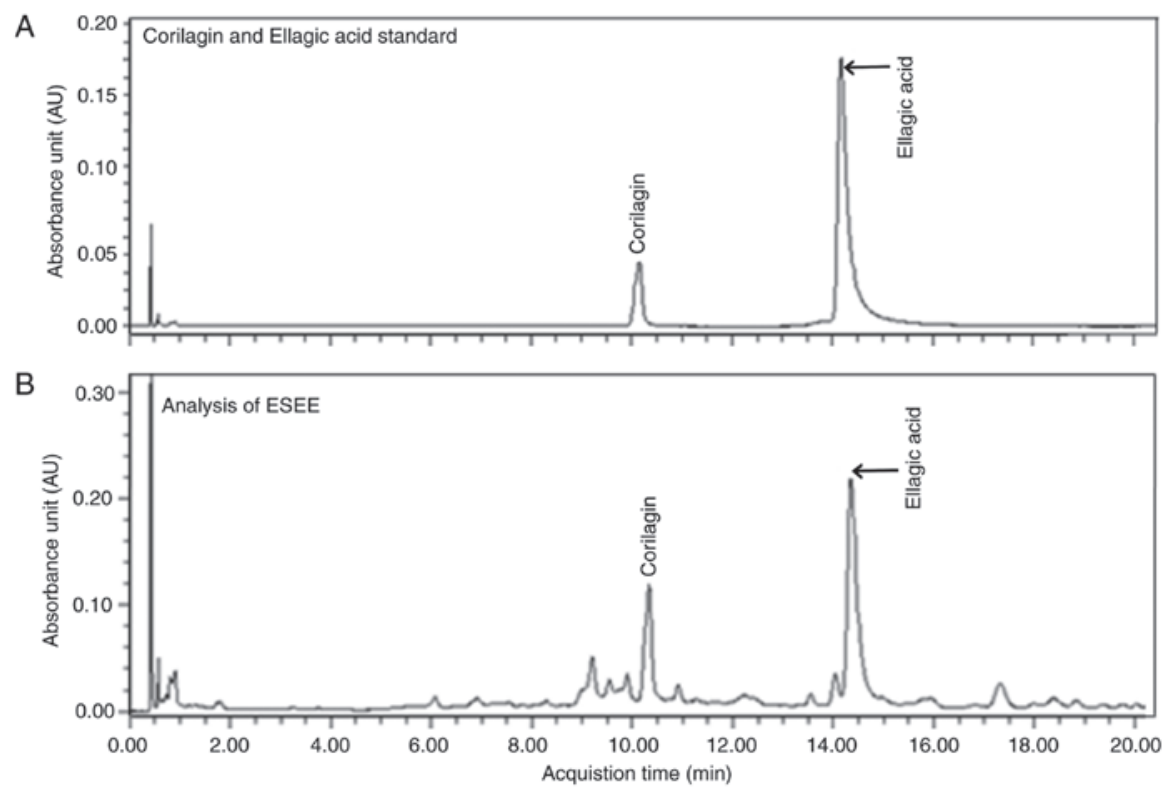

Figure 7. Ultra-pressure liquid chromatography of (A) corilagin, and ellagic acid standards and (B) of ESEE. Corilagin and ellagic acid peaks are indicated. ESEE, ethanol extract of Euphorbia supine.

\section{Discussion}

The induction of obesity in animals via HFD supplementation is the most popular means of mimicking obesity in human, and a number of studies have been conducted using HFD-induced obese mouse models, in which HFD supplementation increases abdominal fat and body weights (22). Previous studies have reported crude plant extracts and natural 
compounds isolated from them induce weight loss and prevent diet-induced obesity $(17,23)$. Although, E. supina is known to have potent anti-oxidant, anti-aging and anti-cancer effects, its effects on obesity have not been previously studied. Therefore, the present study was designed to investigate the effects of ESEE in HFD-fed obese mice.

To the best of our knowledge, this is the first study to report the anti-obesity effects of ESEE in an HFD-fed obese mice model. ESEE was observed to reduce body weight gain and fat accumulation in organs versus HFD-fed mice. Furthermore, ESEE did not affect food intake levels but did reduce the food conversion efficiencies, which indicated that ESEE treatment reduced the abilities of animals to convert food into body mass. ESEE also suppressed weight increases of eWAT, and of organs including the liver, spleen and kidneys versus HFD-fed mice. These findings are in accordance with those of a previous study, in which a capsicoside G-rich fraction from pepper exhibited anti-obesity effects in HFD-induced obese mice (23).

Obesity is associated with the development of fatty liver (24), and an imbalance between food consumption and combustion leads to hepatic steatosis (25). Therefore, H\&E staining was performed to measure the histological morphologies of adipose and liver tissues. ESEE was observed to inhibit adipocyte hypertrophy and the accumulation of lipid droplets in the liver. Furthermore, ESEE reduced hepatic steatosis as evidenced by reductions in the levels of hepatic TG and TC. In addition, ESEE reduced HFD-induced serum markers of fatty liver, including AST and ALT. These findings were similar to those reported for the anti-obesity effect of Gomisin N in HFD-induced obese mice (26). ESEE reduced HFD-induced increases in serum lipid profiles, such as TC, TG and LDLc, and increased serum levels of HDLc, which were in accordance with its observed suppressive effect on HFD-induced fatty liver and hyperlipidemia in HFD-fed mice. WAT synthesizes leptin, which serves important roles in the suppression of food intake and the control of body weight (27), and adiponectin, which regulates glucose levels and serves an important role in hepatic fatty acid oxidation $(28,29)$. Therefore, the levels of leptin and adiponection in ESEE treated HFD-fed mice were examined. The present results demonstrated that ESEE significantly reduced serum leptin levels and increased serum adiponectin levels in HFD-fed mice. These findings concur with those of a previous study, which demonstrated that Triticum aestivum sprouts have an anti-obesity effect in HFD-fed mice (17).

PPAR $\gamma$ and $\mathrm{C} / \mathrm{EBP}-\alpha$ are important transcription factors of adipogenesis (30). PPAR $\gamma$ is expressed predominantly in adipose tissues and serves an important role in adipocyte differentiation, lipid storage, and glucose homeostasis $(31,32)$. PPAR $\gamma$ binds with $\mathrm{C} / \mathrm{EBP}-\alpha$ promoter region and this binding induces the expression of $\mathrm{C} / \mathrm{EBP}-\alpha$, which directly controls adipocyte differentiation (33). In the present study, ESEE significantly inhibited the mRNA and protein expressions of PPAR $\gamma$ and $\mathrm{C} / \mathrm{EBP}-\alpha$, which was previously detected in green tomato extract-treated HFD-induced obese mice (34).

Chemical analysis by UPLC in the present study showed that corilagin and ellagic acid were the main components of ESEE, but other observed peaks were not identified. Many studies have reported the anti-inflammatory, anti-cancer and hepatoprotective effects of corilagin (35-37). Previous studies have also reported that ellagic acid improved hepatic steatosis and suppressed serum resistin levels in obese mice $(38,39)$, and that ellagic acid suppresses lipid accumulation by inhibiting adipogenesis and cell proliferation (40). In a previous study, it was demonstrated that the anti-obesity effect of Geranium thunbergii was due to the presence of components including corilagin and ellagic acid (41). According to the present findings, corilagin and ellagic acid are the major components if ESEE, and therefore, it is hypothesized that these compounds were at least partially responsible for the observed anti-obesity effects of ESEE.

The present study has some limitations that should be noted. First, ESEE was administered at various doses to HFD-fed mice but not ND-fed mice. Second, the effects of corilagin and ellagic acid on HFD-induced obesity were not investigated.

To the best of our knowledge, the present study was the first to demonstrate that ESEE effectively inhibits adipogenesis, and that ESEE contains anti-adipogenic molecules that downregulate transcription factors for adipogenesis, such as $\mathrm{C} / \mathrm{EBP} \alpha$ and PPAR $\alpha / \gamma$. These findings suggest that ESEE possesses anti-obesity effects, and that it may be a promising agent for the treatment of obesity and its metabolic syndrome.

\section{Acknowledgements}

The present study was supported by a 2017 grant from Wonkwang University (Jeonbuk, Korea; grant no. WK-2017-2).

\section{Competing interests}

The authors declare that they have no competing interests.

\section{References}

1. Dorresteijn JA, Visseren FL and Spiering W: Mechanisms linking obesity to hypertension. Obes Rev 13: 17-26, 2012.

2. McCarthy MI: Genomics, Type 2 diabetes, and obesity. N Engl J Med 363: 2339-2350, 2010.

3. Tzotzas T, Evangelou P and Kiortsis DN: Obesity, weight loss and conditional cardiovascular risk factors. Obes Rev 12: e282-e289, 2011.

4. Rocha VZ and Libby P: Obesity, inflammation, and atherosclerosis. Nat Rev Cardiol 6: 399-409, 2009.

5. Yeh WC, Cao Z, Classon M and McKnight SL: Cascade regulation of terminal adipocyte differentiation by three members of the C/EBP family of leucine zipper proteins. Genes Dev 9: 168-181, 1995.

6. Poudel B, Nepali S, Xin M, Ki HH, Kim YH, Kim DK and Lee YM: Flavonoids from Triticum aestivum inhibit adipogenesis in 3T3-L1 cells by upregulating the insig pathway. Mol Med Rep 12: 3139-3145, 2015.

7. Han J, Farmer SR, Kirkland JL, Corkey BE, Yoon R, Pirtskhalava T, Ido Y and Guo W: Octanoate attenuates adipogenesis in 3T3-L1 preadipocytes. J Nutr 132: 904-910, 2002.

8. Poudel B, Lim SW, Ki HH, Nepali S, Lee YM and Kim DK: Dioscin inhibits adipogenesis through the AMPK/MAPK pathway in 3T3-L1 cells and modulates fat accumulation in obese mice. Int J Mol Med 34: 1401-1408, 2014.

9. Hanif MW and Kumar S: Pharmacological management of obesity. Expert Opin Pharmacother 3: 1711-1718, 2002.

10. Padwal RS and Majumdar SR: Drug treatments for obesity: Orlistat, sibutramine, and rimonabant. Lancet 369: 71-77, 2007.

11. Song MY, Lv N, Kim EK, Kwon KS, Yoo YB, Kim JH, Lee SW, Song JH, Lee JH, Lee SK, et al: Antiobesity activity of aqueous extracts of Rhizoma Dioscoreae Tokoronis on high-fat diet-induced obesity in mice. J Med Food 12: 304-309, 2009. 
12. Nugroho A, Rhim TJ, Choi MY, Choi JS, Kim YC, Kim MS and Park HJ: Simultaneous analysis and peroxynitrite-scavenging activity of galloylated flavonoid glycosides and ellagic acid in Euphorbia supina. Arch Pharm Res 37: 890-898, 2014.

13. Han MH, Lee WS, Nagappan A, Kim HJ, Park C, Kim GY, Hong SH, Kim ND, Kim G, Ryu CH, et al: Polyphenols from Korean prostrate spurge Eurphorbia supine induce apoptosis through the Fas-associated extrinsic pathway and activation of ERK in human leukemic U937 cells. Oncol Rep 36: 99-107, 2016

14. Dhanalakshmi C, Manivasagam T, Nataraj J, Justin Thenmozhi A and Essa MM: Neurosupportive role of vanillin, a natural phenolic compound, on rotenone induced neurotoxicity in SH-SY5Y neuroblastoma cells. Evid Based Complement Alternat Med 2015: 626028, 2015.

15. Song Y, Jeong SW, Lee WS, Park S, Kim YH, Kim GS, Lee SJ, Jin JS, Kim CY, Lee JE, et al: Determination of polyphenol components of Korean prostrate spurge (Euphorbia supina) by using liquid chromatography-tandem mass spectrometry: Overall contribution to antioxidant activity. J Anal Methods Chem 2014: 418690, 2014.

16. Ko YS, Lee WS, Joo YN, Choi YH, Kim GS, Jung JM, Ryu CH, Shin SC and Kim HJ: Polyphenol mixtures of Euphorbia supina the inhibit invasion and metastasis of highly metastatic breast cancer MDA-MB-231 cells. Oncol Rep 34: 3035-3042, 2015.

17. Im JY, Ki HH, Xin M, Kwon SU, Kim YH, Kim DK, Hong SP, Jin JS and Lee YM: Anti-obesity effect of Triticum aestivum sprouts extract in high-fat-diet-induced obese mice. Biosci Biotechnol Biochem 79: 1133-1140, 2015.

18. Nepali S, Ki HH, Lee JH, Lee HY, Lee YM and Kim DK: Wheatgrass derived polysaccharide has anti-inflammatory, anti-oxidative and anti-apoptotic effects on LPS-induced hepatic injury in mice. Phytother Res 31: 1107-1116, 2017.

19. Nepali S, Ki HH, Lee JH, Cha JH, Lee YM and Kim DK: Triticum aestivum sprout-derived polysaccharide exerts hepatoprotective effects against ethanol-induced liver damage by enhancing the antioxidant system in mice. Int J Mole Med 40: 1243-1252, 2017

20. Friedewald WT, Levy RI and Fredrickson DS: Estimation of the concentration of low-density lipoprotein cholesterol in plasma without use of the preparative ultracentrifuge. Clin Chem 18 499-502, 1972

21. Nepali S, Son JS, Poudel B,Lee JH,Lee YM and Kim DK: Luteolin is a bioflavonoid that attenuates adipocyte-derived inflammatory responses via suppression of nuclear factor- $\mathrm{\kappa} \mathrm{B} / \mathrm{mitogen}$-activated protein kinases pathway. Pharmacogn Mag 11: 627-635, 2015.

22. Perez Gutierrez RM, Madrigales Ahuatzi D, Horcacitas Mdel C, Garcia Baez E, Cruz Victoria T and Mota-Flores JM: Ameliorative effect of hexane extract of Phalaris canariensis on high fat diet-induced obese and streptozotocin-induced diabetic mice. Evid Based Complement Alternat Med 2014: $145901,2014$.

23. Sung J, Jeong HS and Lee J: Effect of the Capsicoside G-rich Fraction from Pepper (Capsicum annuum L.) seeds on high-fat diet-induced obesity in mice. Phytother Res 30: 1848-1855, 2016

24. Haque $\mathrm{M}$ and Sanyal AJ: The metabolic abnormalities associated with non-alcoholic fatty liver disease. Best Pract Res Clin Gastroenterol 16: 709-731, 2002.

25. Reddy JK and Rao MS: Lipid metabolism and liver inflammation. II. Fatty liver disease and fatty acid oxidation. Am J Physio Gastrointest Liver Physiol 290: G852-G858, 2006.
26. Jang MK, Yun YR, Kim JH, Park MH and Jung MH: Gomisin N inhibits adipogenesis and prevents high-fat diet-induced obesity. Sci Rep 7: 40345, 2017.

27. Maffei M, Halaas J, Ravussin E, Pratley RE, Lee GH, Zhang Y, Fei H, Kim S, Lallone R, Ranganathan S, et al: Leptin levels in human and rodent: Measurement of plasma leptin and ob RNA in obese and weight-reduced subjects. Nat Med 1: 1155-1161, 1995.

28. Combs TP, Berg AH, Obici S, Scherer PE and Rossetti L: Endogenous glucose production is inhibited by the adipose-derived protein Acrp 30. J Clin Invest 108: 1875-1881, 2001.

29. Pajvani UB and Scherer PE: Adiponectin: Systemic contributor to insulin sensitivity. Curr Diab Rep 3: 207-213, 2003.

30. Soukas A, Socci ND, Saatkamp BD, Novelli S and Friedman JM: Distinct transcriptional profiles of adipogenesis in vivo and in vitro. J Biol Chem 276: 34167-34174, 2001.

31. Schoonjans K, Staels B and Auwerx J: The peroxisome proliferator activated receptors (PPARS) and their effects on lipid metabolism and adipocyte differentiation. Biochim Biophys Acta 1302: 93-109, 1996.

32. Rosen ED, Walkey CJ, Puigserver P and Spiegelman BM: Transcriptional regulation of adipogenesis. Genes Dev 14: 1293-1307, 2000

33. Wu Z, Xie Y, Bucher NL and Farmer SR: Conditional ectopic expression of C/EBP beta in NIH-3T3 cells induced PPAR gamma and stimulates adipogenesis. Genes Dev 9: 2350-2363, 1995.

34. Choi KM, Lee YS, Shin DM, Lee S, Yoo KS, Lee MK, Lee JH, Kim SY, Lee YM, Hong JT, et al: Green tomato extract attenuates high-fat-diet-induced obesity through activation of the AMPK pathway in C57BL/6 mice. J Nutr Biochem 24: 335-342, 2013.

35. Li HR, Liu J, Zhang SL, Luo T, Wu F, Dong JH, Guo YJ and Zhao L: Corilagin ameliorates the extreme inflammatory status in sepsis through TLR4 signaling pathways. BMC Complement Alter Med 17: 18, 2017.

36. Attar R, Cincin ZB, Bireller ES and Cakmakoglu B: Apoptotic and genomic effects of corilagin on SKOV3 ovarian cancer cell line. Oncol Targets Ther 10: 1941-1946, 2017.

37. Liu FC, Chaudry IH and Yu HP: Hepatoprotective effects of corilagin following hemorrhagic shock are through Akt-dependent pathway. Shock 47: 346-351, 2017.

38. Yoshimura Y, Nishii S, Zaima N, Moriyama T and Kawamura Y: Ellagic acid improves hepatic steatosis and serum lipid composition through reduction of serum resistin levels and transcriptional activation of hepatic ppara in obese, diabetic KK-A(y) mice. Biochem Biophys Res Commun 434: 486-491, 2013.

39. Panchal SK, Ward L and Brown L: Ellagic acid attenuates high-carbohydrate, high-fat diet-induced metabolic syndrome in rats. Eur J Nutr 52: 559-568, 2013.

40. Woo MS, Choi HS, Seo MJ, Jeon HJ and Lee BY: Ellagic acid suppresses lipid accumulation by suppressing early adipogenic events and cell cycle arrest. Phytother Res 29: 398-406, 2015.

41. Sung YY, Yoon T, Yang WK, Kim SJ and Kim HK: Anti-obesity effects of Geranium thunbergii extract via improvement of lipid metabolism in high-fat diet-induced obese mice. Mol Med Rep 4: 1107-1113, 2011. 